\title{
Impact of COVID-19 lockdown on ambient air quality in megacities of India and implication for air pollution control strategies
}

\author{
Khaiwal Ravindra ${ }^{1}(1) \cdot$ Tanbir Singh $^{2} \cdot$ Akash Biswal $^{2,3} \cdot$ Vikas Singh $^{3} \cdot$ Suman $_{\text {Mor }^{2}}$ \\ Received: 30 June 2020 / Accepted: 20 November 2020 / Published online: 7 January 2021 \\ (C) Springer-Verlag GmbH Germany, part of Springer Nature 2021
}

\begin{abstract}
The impact of restrictions during various phases of COVID-19 lockdown on daily mean $\mathrm{PM}_{2.5}$ concentration in five Indian megacities (New Delhi, Chennai, Kolkata, Mumbai, and Hyderabad) was studied. The impact was studied for pre-lockdown (1st Mar-24th Mar 2020), lockdown (25th Mar-31st May 2020), and unlocking (1st Jun-31st Aug 2020) phases. The lockdown period comprises 4 lockdown phases with distinct measures, whereas the unlocking period had 3 phases. $\mathrm{PM}_{2.5}$ concentration reduced significantly in all megacities and met the national standards during the lockdown period. The maximum reduction in $\mathrm{PM}_{2.5}$ level was observed in Kolkata (62\%), followed by Mumbai (49\%), Chennai (34\%), and New Delhi (26\%) during the lockdown period. Comparatively, Hyderabad exhibited a smaller reduction in $\mathrm{PM}_{2.5}$ concentration, i.e., $10 \%$. The average $\mathrm{PM}_{2.5}$ levels during the lockdown in the peak hour (i.e., 07:00-11:00 h) in New Delhi, Chennai, Kolkata, Mumbai, and Hyderabad decreased by $21.3 \%, 48.5 \%, 63.4 \%, 56.4 \%$, and $23.8 \%$, respectively, compared to those before lockdown period. During the unlocking period, except for Chennai, all megacities showed a reduction in average $\mathrm{PM}_{2.5}$ levels compared to concentrations in the lockdown period, but these reductions were mainly linked with monsoon rains in India. The current study provided an opportunity to study air pollution in the absence of major anthropogenic activities and during limited activities in monsoon season having an ecological design. The study reports a new baseline of $\mathrm{PM}_{2.5}$, except for monsoon, and explores this knowledge to plan future air pollution reduction strategies. The study also discusses how this new learning of knowledge could strengthen air pollution control policies for better air quality and sustainability.
\end{abstract}

Keywords COVID-19 $\cdot$ Coronavirus $\cdot$ Lockdown $\cdot$ Air quality $\cdot$ Megacities $\cdot \mathrm{PM}_{2.5}$

Highlights

- Studied the impact of COVID-19 lockdown on $\mathrm{PM}_{2.5}$ levels in five

Indian megacities

- An ecological study design in the absence of major anthropogenic activities

- A fall of 10 to $62 \%$ was noticed in all five Indian megacities during lockdown.

- Peak hours $\mathrm{PM}_{2.5}$ levels during lockdown decreased by 21.3 to $63.4 \%$ compared to pre lockdown period.

- The study identifies a new baseline level of $\mathrm{PM}_{2.5}$ except observed during monsoon.

- The study aims to support short- and long-term air pollution reduction strategies.

Responsible Editor: Philippe Garrigues

Khaiwal Ravindra

khaiwal@yahoo.com; khaiwal.ravindra@pgimer.edu.in

1 Department of Community Medicine and School of Public Health, Post Graduate Institute of Medical Education and Research (PGIMER), Chandigarh 160012, India
2 Department of Environment Studies, Panjab University, Chandigarh 160014, India

3 National Atmospheric Research Laboratory, Gadanki, Chandigarh 517502, India 


\section{Introduction}

As a preventive step to contain the COVID-19 disease, an unprecedented lockdown was imposed on the 25th of March 2020 in India, and then it was extended phase-wise until the 31st of May 2020. All non-essential sectors were closed, such as schools, colleges, and industries, including transportation in the entire country, making it the most extended lockdown in the world. This lockdown has also brought some unforeseen environmental benefits, including improvement in air quality since the start of the lockdown (Arora et al. 2020; Singh et al. 2020a).

In the past, several short- and long-term measures to improve air quality were taken globally. Some of these steps include the 2016 odd-even policy in New Delhi, India, to reduce vehicular air pollution (Chowdhury et al. 2017), and regulation and closure of traffic including industries (temporary and permanent) during the 2008 Beijing Olympic Games (Chen et al. 2013). It was observed that during the Beijing Olympics, the air quality in the city improved by $24.9 \%$ (Chen et al. 2013). The odd-even policy in New Delhi shows a marginal change in air quality improvement (Sharma et al. 2017; Chowdhury et al. 2017). Levy et al. (2006) also observed a small but measurable influence on air quality during the Democratic National Convention in Boston in 2004 due to road closures. Ravindra et al. (2006) highlighted the changes in air quality associated with policy implications such as adopting clean fuel in public transport or other measures (Ravindra et al. 2020; Sembhi et al. 2020). These studies highlight that such events help to understand air pollution and sources better. Similarly, Li et al. (2019) also examine the impact of air pollution control measures on various ambient pollutants during the G-20 summit in Hangzhou in 2016. These observations were in agreement with the APEC summit 2014 in China, where short-term improvement in air quality was observed by Huang et al. (2015). In Chile, the regulatory plans like PDAs (Environmental Decontamination Plans) on $\mathrm{PM}_{2.5}$ show up to an $8 \mu \mathrm{g} \mathrm{m}^{-3}$ reduction in $\mathrm{PM}_{10}$ levels (Mardones and Cornejo 2020).

Short-term closure of vehicular traffic ( $36 \mathrm{~h})$ in the South Coast Air Basin, USA, the regional $\mathrm{PM}_{2.5}$ reduced 18-36\% (Quiros et al. 2013). Similar results were reported in Yeongdong, South Korea, during a temporary shutdown of coal-fired power plants resulting in around $4.4 \mu \mathrm{g} \mathrm{m}^{-3}$ reduction in $\mathrm{PM}_{2.5}$ (Yi and Sung 2018). In agreement with Gurjar et al. (2016), Ravindra et al. (2016), and Bhargava et al. (2018), Vardoulakis et al. (2018) also highlighted that multiple measures to regulate traffic-related pollution not only help in air quality improvement but also has various public health benefits. However, most of the above interventions were short-term and having limited restrictions, e.g., closure of a road or some industries.
The current study examines the impact of long-term lockdown on $\mathrm{PM}_{2.5}$ levels in India's five megacities and changes in $\mathrm{PM}_{2.5}$ levels in the unlocking period. The unfortunate spread of coronavirus and subsequent lockdown to prevent the spread of the virus in the community led to the closure of most anthropogenic activities. This provides an opportunity as an ecological study to ascertain the baseline air pollution levels and extend the learning to formulate evidence-based short- and long-term policies to minimize the air pollution and associated premature death and diseases.

\section{Data and methodology}

The current study examines the air pollution data $\left(\mathrm{PM}_{2.5}\right)$ being collected by the US Embassy and consulates in India from the year 2016-2020. To study the impact of lockdown on daily mean $\mathrm{PM}_{2.5}$ concentrations, the period from the 1 st to the 24th of March 2020 was considered pre-lockdown, from the 25th of March to the 31st of May 2020 as a lockdown period, and from the 1st of June to the 31st of August 2020 as unlocking (partial-relaxation) period. The average matching period (2016-2019) was taken as business as usual (BAU) for comparison to study the air quality changes during the lockdown period. The US Embassy and consulates provide high-resolution air quality data over many cities worldwide, including India. The $\mathrm{PM}_{2.5}$ levels are being measured using BAM-1020 (Beta Attenuation Monitor; MetOne, USA).

In India, BAM is positioned in the US Embassy, New Delhi, including other consulates in Chennai, Kolkata, Hyderabad, and Mumbai (Singh et al. 2020b). Out of these five megacities, Delhi is India's national capital, and the rest of the cities are the administrative capital of respective states. These megacities represent major geographical locations of India, and this provides an opportunity to conduct valid scientific analysis considering the diverse Indian climate. All monitoring sites provide hourly $\mathrm{PM}_{2.5}$ data since March 2015. The hourly $\mathrm{PM}_{2.5}$ data was downloaded from the 1st of March 2020 to the 31st of August 2020 from all five locations were examined for inconsistency and validated before analysis. Meteorological data of rainfall, relative humidity (RH), and average temperature (AT) were downloaded from www.ogimet.com.

\section{Results and discussion}

\section{Effect of lockdown on daily mean $\mathrm{PM}_{2.5}$ levels}

The impact of lockdown on daily mean $\mathrm{PM}_{2.5}$ concentrations was studied before lockdown (1st March-24th March), during different phases of lockdown (25th March-31st May), and during unlocking stages (1st June-31 August) in five 
megacities of India. The daily average concentration of $\mathrm{PM}_{2.5}$ in Chennai, Hyderabad, Kolkata, Mumbai, and New Delhi before the lockdown period was $21.8 \pm 10.0 \mu \mathrm{g} \mathrm{m}^{-3}, 34.3 \pm$ $10.9 \mu \mathrm{g} \mathrm{m}^{-3}, 65.1 \pm 30.1 \mu \mathrm{g} \mathrm{m}^{-3}, 48.6 \pm 20.6 \mu \mathrm{g} \mathrm{m}^{-3}$, and $60.0 \pm 18.4 \mu \mathrm{g} \mathrm{m}^{-3}$, which reduced to $14.4 \pm 8.7 \mu \mathrm{g} \mathrm{m}^{-3}$, $30.9 \pm 8.1 \mu \mathrm{g} \mathrm{m}^{-3}, 24.7 \pm 13.7 \mu \mathrm{g} \mathrm{m}^{-3}, 24.6 \pm 9.7 \mu \mathrm{g} \mathrm{m}^{-3}$, and $44.2 \pm 16.3 \mu \mathrm{g} \mathrm{m}^{-3}$ as depicted in Table 1.

This indicates that $\mathrm{PM}_{2.5}$ levels decrease significantly, and all the locations met the Indian air quality standard $\left(60 \mu \mathrm{g} \mathrm{m}^{-3}\right.$ for $24 \mathrm{~h}$ average). The maximum reduction in $\mathrm{PM}_{2.5}$ concentrations was observed in Kolkata (62\%), followed by Mumbai (49\%), Chennai (34\%), and New Delhi (26\%). Comparatively, Hyderabad exhibited a slight reduction in $\mathrm{PM}_{2.5}$ concentration, i.e., $10 \%$. Graphical representation of daily average data (Fig. 1) of five megacities shows a gradual declining trend after the lockdown period. It is important to note that during the lockdown period, all major anthropogenic and industrial activities such as vehicles, mini industries, restaurants, and street vendors were closed, providing an opportunity to conduct a baseline monitoring of $\mathrm{PM}_{2.5}$ levels in all megacities. The various lockdown phases have a difference in restrictions resulting in variation in $\mathrm{PM}_{2.5}$ levels in different stages of lockdown. In the first phase of lockdown, all human activities were halted except for emergency services (Singh et al. 2020a; Mor et al. 2020). After that, in consecutive phases, increased activities, like movements of people stuck in lockdown, relaxation in timings to buy market goods, and the opening of essential industries, were allowed with limitations.

Sharma and Dikshit (2016) reported that significant contributors to annual $\mathrm{PM}_{2.5}$ emissions in Delhi include road dust (38\%), vehicle exhaust emissions (20\%), domestic fuel burning $(12 \%)$, and industries (11\%). Furthermore, crop residue burning also affects during specific seasons (Singh et al. 2020c, 2020d). The other studies from Delhi megacity reported vehicular emissions (exhaust and non-exhaust) have a significant contribution to Delhi's $\mathrm{PM}_{2.5}$ load varies up to 60\% (Sahu et al. 2011; Singh et al. 2020e; Gargava and Rajagopalan 2016). In lockdowns 1 and 2 , it was observed that there is only restricted vehicular movement, and only essential services like police, hospital, army, and other emergency transport vehicles were allowed. This restricted vehicle movement resulted in a significant reduction in the exhaust and non-exhaust emissions, which is one of the significant contributors to the total PM emissions.

Similarly, in other megacities like Mumbai, roadside dust, vehicles, and construction have a significant contribution to PM emissions, which varies from 29 to $47 \%, 8-26 \%$, and 8$26 \%$, respectively (CPCB 2011). In Chennai, roadside dust and vehicles have significant contributions varying from 6 to $27 \%$ and 35 to $48 \%$, respectively (Gargava and Rajagopalan 2016). The absence of all these significant contributors to PM

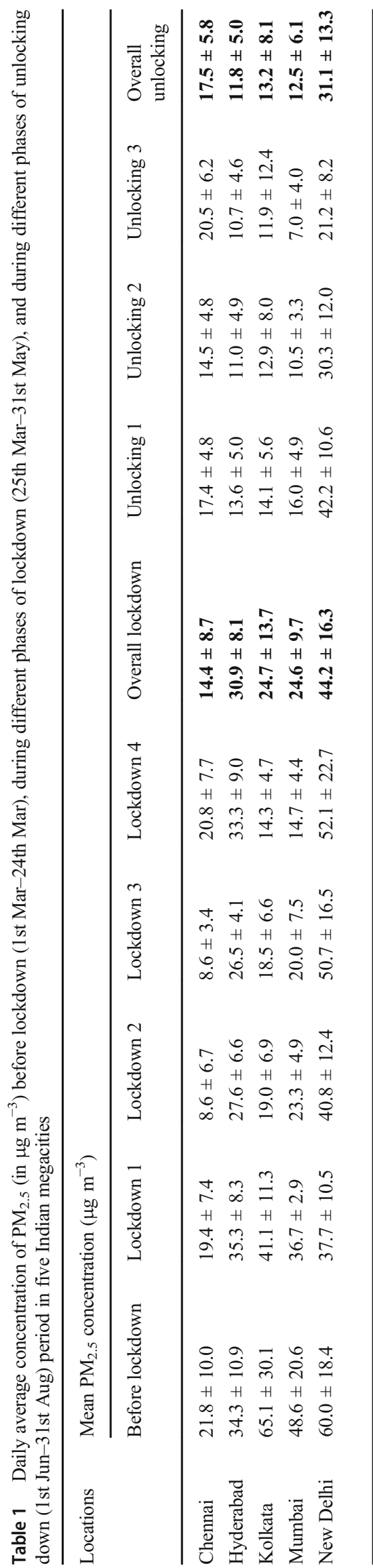



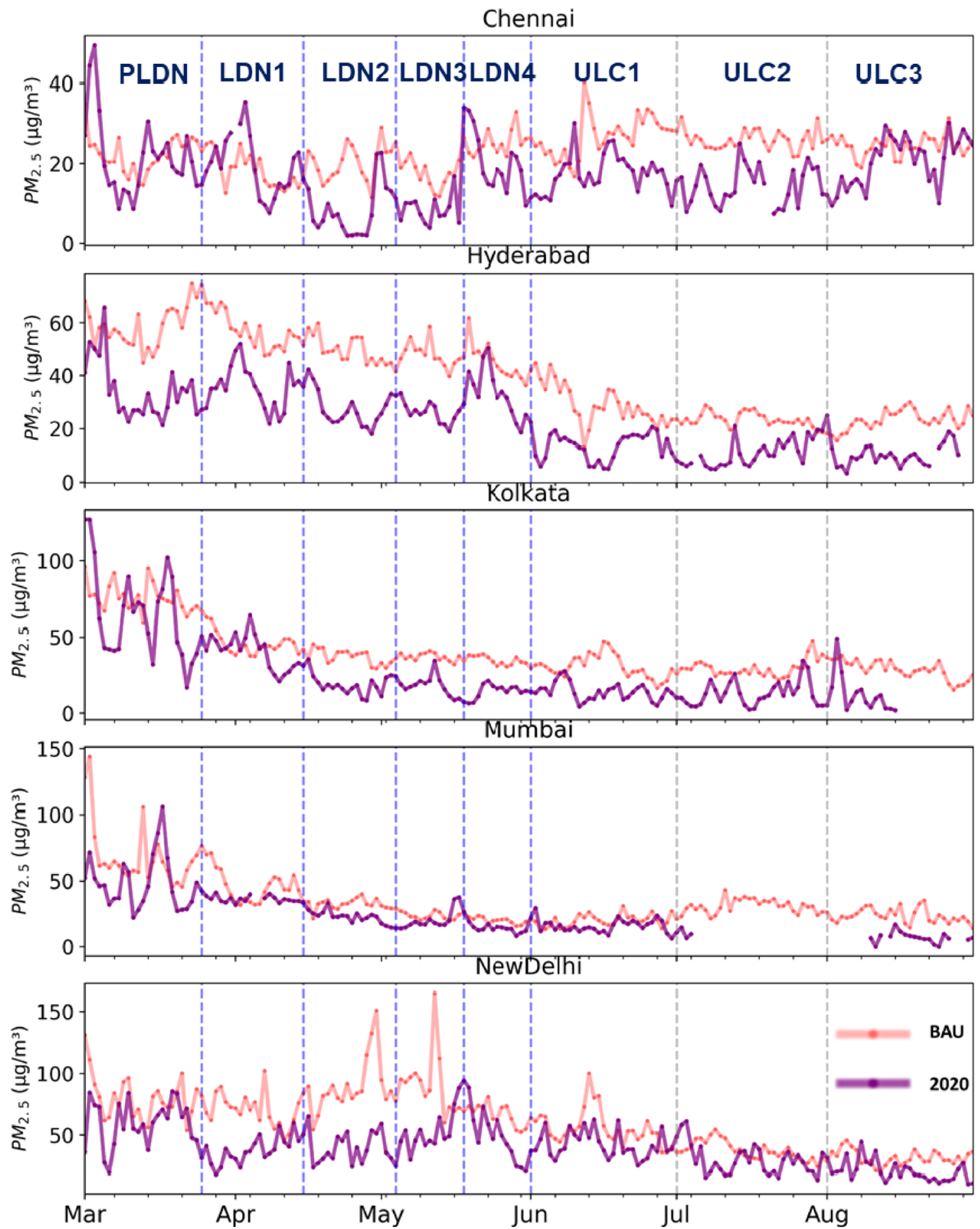

Fig. 1 Daily average concentration of $\mathrm{PM}_{2.5}$ (in $\mu \mathrm{g} \mathrm{m}^{-3}$ ) in five Indian megacities before (1st March-24th March), during lockdown (25th March-31st May) and unlocking (1st June-31st August) period along with its comparison with business as usual (BAU) concentrations from the year 2016-2019

concentration led to a decrease in PM levels. Contrary to these factors, household emissions might have increased during the lockdown period. In Hyderabad, vehicular exhaust (31\%) and resuspension of dust (26\%) are also major contributors to ambient $\mathrm{PM}_{2.5}$ levels, followed by combustion (9\%), industries (7\%), and waste burning (6\%) (Gummeneni et al. 2011). Furthermore, in India, during summer seasons, planetary boundary layer height increases, and wind speeds help in reducing the $\mathrm{PM}_{2.5}$ levels (Sreekanth et al. 2018).

\section{Diurnal variation in $\mathrm{PM}_{2.5}$ concentrations}

Figure 2 shows the diurnal variations in $\mathrm{PM}_{2.5}$ average hourly concentration before lockdown, during the lockdown and 
unlocking period in all five megacities. Supplementary Table 1 provides a more detailed analysis as dicussed. The highest $\mathrm{PM}_{2.5}$ concentrations $\left(90.3 \mu \mathrm{g} \mathrm{m}^{-3}\right)$ were observed during morning rush hours (09:00 h) in New Delhi, which later gradually decreases to $64 \mu \mathrm{g} \mathrm{m}^{-3}$ in lockdown and $31.2 \mu \mathrm{g} \mathrm{m}^{-3}$ in the unlocking period. Similarly, in Chennai, $\mathrm{PM}_{2.5}$ concentration peaks at $08: 00 \mathrm{~h}\left(39.4 \mu \mathrm{g} \mathrm{m}^{-3}\right)$ and levels reduced later from $17.2 \mu \mathrm{g} \mathrm{m}^{-3}$ and $18.0 \mu \mathrm{g} \mathrm{m}^{-3}$ in lockdown and unlocking period. Other megacities, i.e., Kolkata, Mumbai, and Hyderabad, also depict the highest levels of $\mathrm{PM}_{2.5}$ during morning hours at 00:00 h, 09:00 h, and 09:00 h having peak $\mathrm{PM}_{2.5}$ concertation of 84.7, 71.0, and $43.6 \mathrm{mg} \mathrm{m}^{-3}$. During the lockdown, the $\mathrm{PM}_{2.5}$ peaks in these cities shifted to 14:00 h, 22:00 h, and 22:00 h, having $\mathrm{PM}_{2.5}$ peak concentrations of 29.3, 27.8, and $37.9 \mu \mathrm{g} \mathrm{m}^{-3}$.

Considering 07:00 am to 11:00 am as peak rush hour, the average $\mathrm{PM}_{2.5}$ concentrations in Chennai, Hyderabad, Kolkata Mumbai, and New Delhi in this period have decreased by $48.5 \%, 23.8 \%, 63.4 \%, 56.37$, and $21.3 \%$, respectively. A late evening hour (after 22:00 h) peak of $\mathrm{PM}_{2.5}$ was observed in all megacities, as shown in Fig. 2. This could be linked to the decrease in night temperature and boundary level height. The current study indicates that $\mathrm{PM}_{2.5}$ concentrations in megacities fall significantly and show the impact of various anthropogenic activities. During the lockdown period, regional and local sources such as emission from the rural household due to solid biomass fuel use may contribute to $\mathrm{PM}_{2.5}$ levels. These emissions are reported to dominate in the rural areas of India (Sidhu et al. 2017; Ravindra and Smith 2018; KaurSidhu et al. 2020, and Ravindra et al. 2019a, 2019b).
However, air pollution reduction was noticed all over India, and hence, these contributions will have a minimum impact on the megacities' air quality.

In the pre-lockdown period (PLDN), the highest average $\mathrm{PM}_{2.5}$ concentration in New Delhi, Mumbai, and Hyderabad was at morning hours, i.e., $09: 00 \mathrm{~h}$ as $90.3 \mu \mathrm{g} \mathrm{m}^{-3}, 71 \mu \mathrm{g} \mathrm{m}^{-3}$, and $43.6 \mu \mathrm{g} \mathrm{m}^{-3}$, respectively. In contrast, the highest average $\mathrm{PM}_{2.5}$ concentration in Chennai was observed at $08: 00 \mathrm{~h}$ as $39.4 \mu \mathrm{g} \mathrm{m}^{-3}$ and in Kolkata at 00:00 h as $84.7 \mu \mathrm{g} \mathrm{m}^{-3}$. In business as usual (BAU-PM) trends for matching period (2016-2019), the peak hour of $\mathrm{PM}_{2.5}$ concentration in all megacities, i.e., Chennai, Hyderabad, Kolkata Mumbai, and New Delhi, was at 08:00 $\mathrm{h}$ having an average concentration of $39.2 \mu \mathrm{g} \mathrm{m}^{-3}, 77.8 \mu \mathrm{g} \mathrm{m}^{-3}, 87.3 \mu \mathrm{g} \mathrm{m}^{-3}, 91.4 \mu \mathrm{g} \mathrm{m}^{-3}$, and $145.2 \mu \mathrm{g} \mathrm{m}^{-3}$ respectively. During the lockdown, the highest average $\mathrm{PM}_{2.5}$ concentration in New Delhi was at $08: 00 \mathrm{~h}$ as $70.1 \mu \mathrm{g} \mathrm{m}^{-3}$, which was $122.7 \mu \mathrm{g} \mathrm{m}^{-3}$ in BAU matching period (BAU-LM). Similarly, in Chennai, the highest average $\mathrm{PM}_{2.5}$ concentration during lockdown was at 07:00 $\mathrm{h}$ as $17.4 \mu \mathrm{g} \mathrm{m}^{-3}$, which was earlier at 19:00 h as $23.4 \mathrm{~m} \mathrm{~m}^{-3}$ in BAU-LM. In Kolkata, during lockdown, the highest average $\mathrm{PM}_{2.5}$ concentration was observed at 14:00 $\mathrm{h}\left(29.3 \mu \mathrm{g} \mathrm{m}^{-3}\right)$, whereas in Mumbai, it was at $04: 00 \mathrm{~h}$ as $14.7 \mu \mathrm{g} \mathrm{m}^{-3}$ and in Hyderabad at 22:00 $\mathrm{h}$ as $37.9 \mu \mathrm{g} \mathrm{m}^{-3}$.

In contrast, in BAU-LM PM 2.5 , the highest concentrations in Kolkata, Mumbai, and Hyderabad were at 15:00 h as 45.5, at $08: 00 \mathrm{~h}$ as $39.7 \mu \mathrm{g} \mathrm{m}^{-3}$, and at $22: 00 \mathrm{~h}$ as $64.0 \mu \mathrm{g} \mathrm{m}^{-3}$, respectively. In the unlock period, $\mathrm{PM}_{2.5}$ highest concentration in New Delhi was at 23:00 $\mathrm{h}$ as $34.9 \mu \mathrm{g} \mathrm{m}^{-3}$, Chennai at
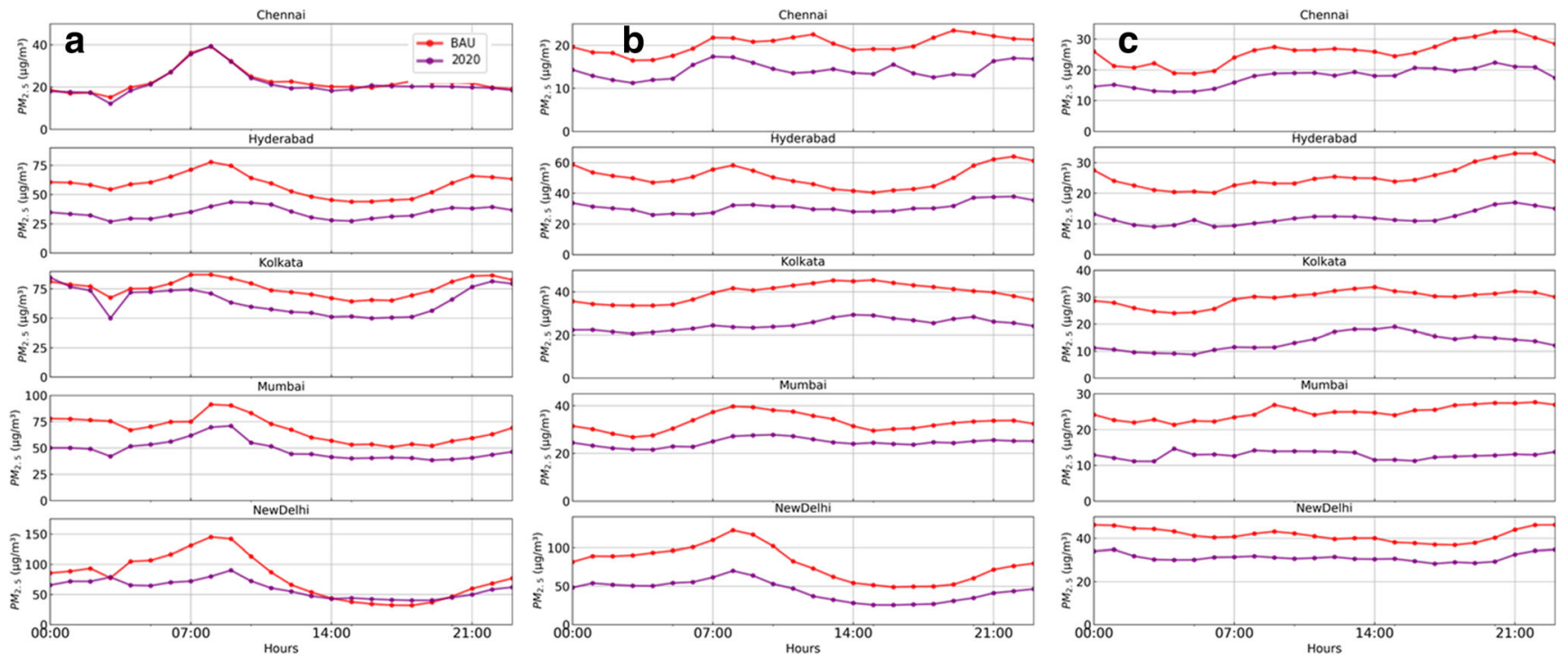

Fig. 2 Diurnal variations in the average hourly concentration of $\mathrm{PM}_{2.5}$ (in $\mu \mathrm{g} \mathrm{m}^{-3}$ ) before (1st March-24th March) (a), during lockdown (25th March-31st May) (b), and unlocking period (1st June-31st August) (c) along with its comparison with business as usual (BAU) concentrations

from the year 2016-2019 in five Indian megacities (where red line represents $B A U P M_{2.5}$ concentration trend, and the blue line represents $P M_{2.5}$ concentration in 2020 during different periods) 
20:00 h as $22.4 \mu \mathrm{g} \mathrm{m}^{-3}$, Kolkata at 15:00 h as $19.0 \mathrm{\mu g} \mathrm{m}^{-3}$, Mumbai at 10:00 $\mathrm{h}$ as $27.8 \mathrm{\mu g} \mathrm{m}^{-3}$, and Hyderabad at 21:00 h as $17.0 \mu \mathrm{g} \mathrm{m}^{-3}$. In the BAU matching period of unlocking (BAU-UM), the highest $\mathrm{PM}_{2.5}$ concentration in Chennai and Hyderabad was at 21:00 h as $32.7 \mu \mathrm{g} \mathrm{m}^{-3}$ and $33 \mu \mathrm{g} \mathrm{m}^{-3}$, in Kolkata at 14:00 h as $33.8 \mu^{g^{-3}}$, in Mumbai at 22:00 as $27.7 \mathrm{\mu g} \mathrm{m}^{-3}$, and in New Delhi at 23:00 $\mathrm{h}$ as $46.3 \mu \mathrm{g} \mathrm{m}^{-3}$. The change in peak hours of $\mathrm{PM}_{2.5}$ clearly shows the impacts of restriction timings in lockdown and unlocking period.
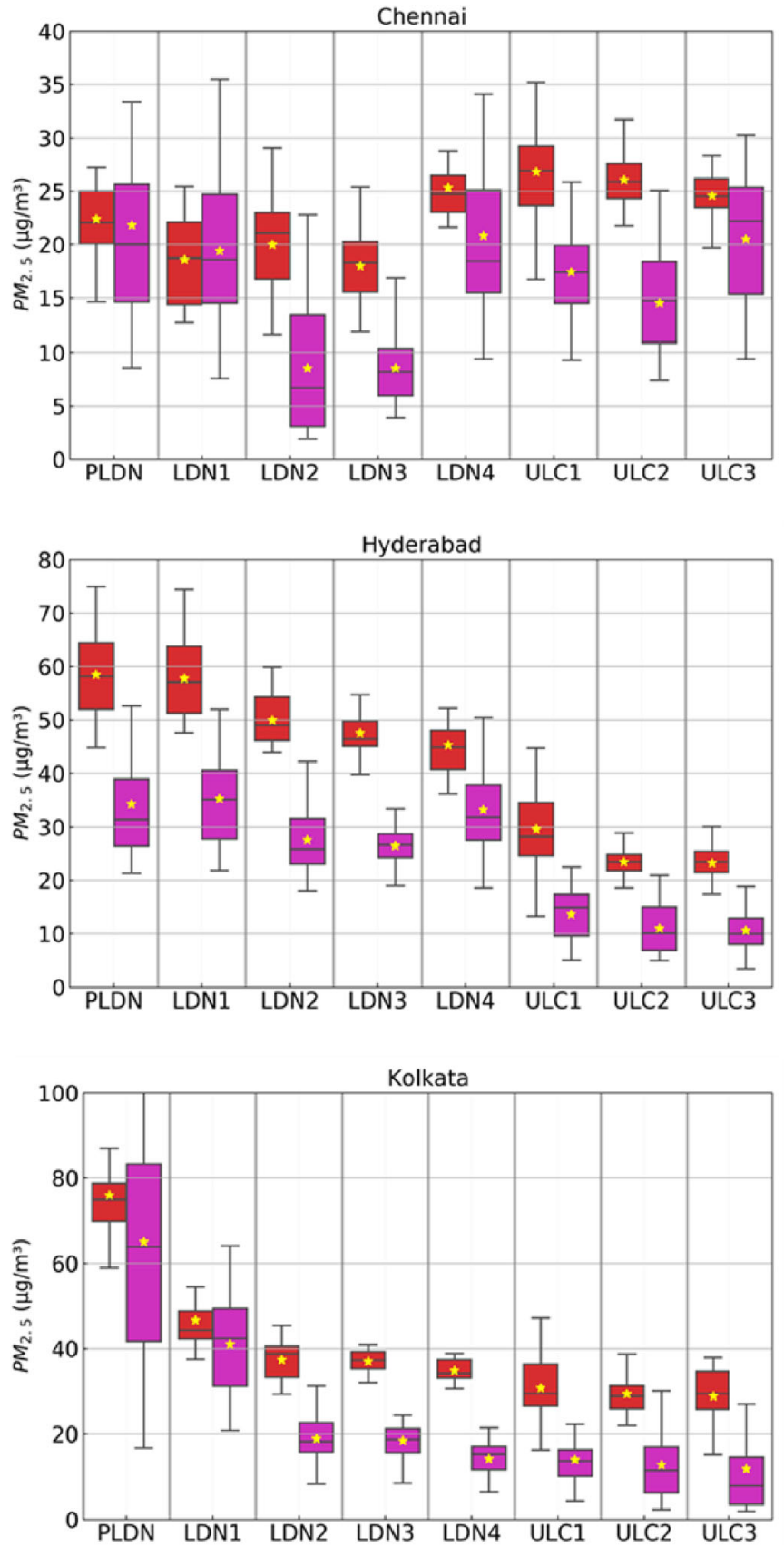

\section{Variation in $\mathbf{P M}_{2.5}$ levels during different phases of lockdown and unlocking period}

The study analyzed the variations in $\mathrm{PM}_{2.5}$ levels during the various lockdown and unlocking phases (Fig. 3) where the period from the 25th of March 2020 to the 14th of April 2020 was lockdown 1 (LDN1), from the 15th of April 2020 to the 3rd of May 2020 was lockdown 2 (LDN2), from the 4 th of May 2020 to the 17th of May 2020 was lockdown 3 (LDN3), and from the 18th of May 2020 to the 31st of May 2020 was lockdown 4 (LDN4). The unlocking took place
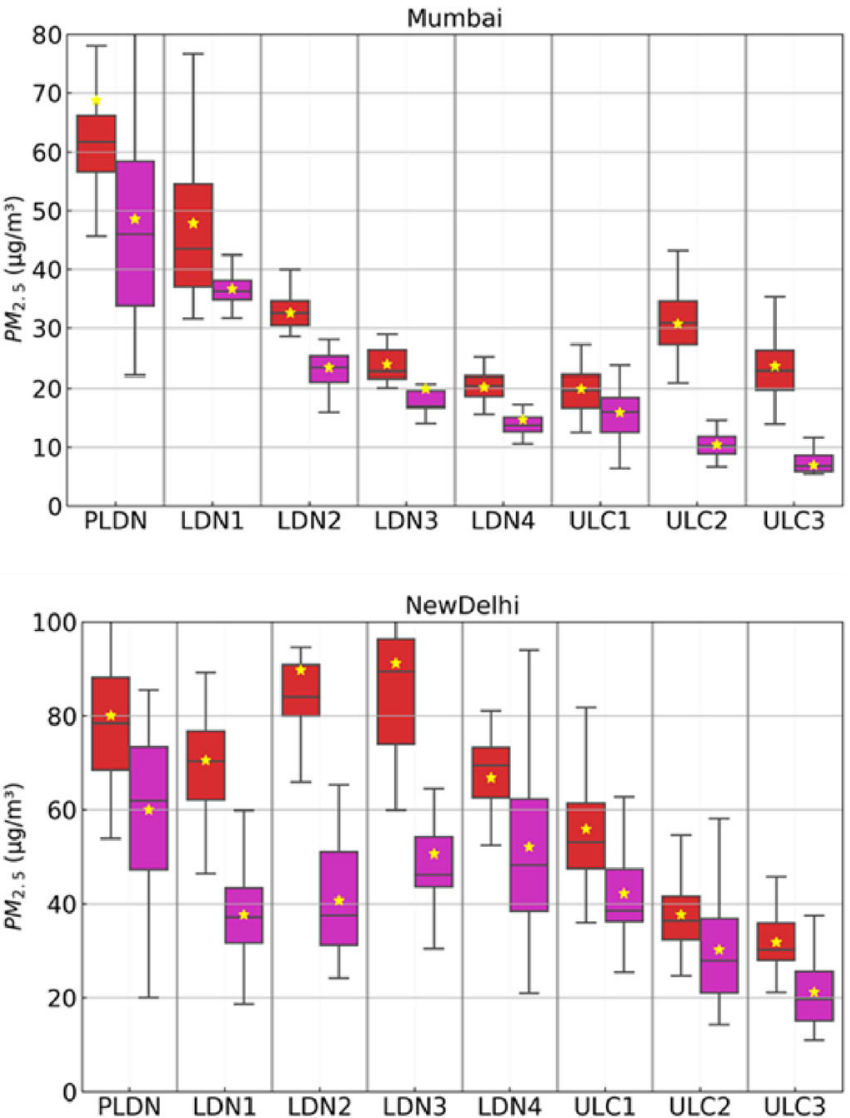

Fig. 3 Boxplot of variation in concentration of $\mathrm{PM}_{2.5}\left(\mu \mathrm{g} \mathrm{m}{ }^{-3}\right)$ in five Indian megacities during different phases of study and its comparison with business as usual (BAU) $\mathrm{PM}_{2.5}$ concentrations from the year 2016-2019 
in 3 phases in which unlocking 1 (ULC1) was from the 1st of June 2020 to the 30th of June 2020, followed by unlocking 2 (ULC2) from the 1st of July 2020to the 31st of July 2020, and unlocking 3 (ULC3) from the 1st of August 2020 to the 31 st of August 2020. Table 2 shows the percentage change in $\mathrm{PM}_{2.5}$ concentration during different phases of lockdown and unlocking period in five Indian megacities.

In lockdown 1 with stricter restrictions, the concentration of $\mathrm{PM}_{2.5}$ decreased significantly (compared to that before the lockdown period) in all megacities except for Hyderabad. The reduction was highest in New Delhi (37.1\%), followed by Kolkata (36.9\%), Mumbai (24.4\%), and Chennai (11.1\%), whereas in Hyderabad, the concentration increased by $2.9 \%$. In the other three phases of lockdowns, the $\mathrm{PM}_{2.5}$ showed a declining trend in all megacities. Kolkata shows the highest reduction in lockdowns 2,3 , and 4 as $70.9 \%, 71.6 \%$, and $78.1 \%$, respectively, whereas the minimum decrease in PM concentration was observed in lockdowns 2 and 4 in Hyderabad.

In the unlocking period, all megacities showed a declining concentration of $\mathrm{PM}_{2.5}$ except for Chennai compared to the average concentration of $\mathrm{PM}_{2.5}$ during the lockdown period. Hyderabad shows a maximum reduction of $60.9 \%$, whereas Chennai shows an increment of $22.7 \%$. The impact of monsoons on $\mathrm{PM}_{2.5}$ concentration is visible from the results and discussed in the subsequent section. The percentage variations in $\mathrm{PM}_{2.5}$ concentration within lockdown phases are shown in Supplementary Table 2, and it can be seen that concentration increases as the lockdown period increases in many megacities. This may be due to relaxations, which were given in the last phases of lockdown as some commercial activities started during this period.

There was a significant decline in the concentration of $\mathrm{PM}_{2.5}$ in all phases of the study compared to BAU data trends. Compared to matching BAU data, the percentage decline in PM2.5 levels in the pre-lockdown period was 2.6-41.3\%. The percentage decline during the lockdown period was 25.344.3\%. In the unlocking period, $\mathrm{PM}_{2.5}$ decline $25.3-55.7 \%$ in various megacities. Table 3 depicts the average $\mathrm{PM}_{2.5}$ concentration during different phases of study and its comparison with the matching business as usual (BAU) period along with the percentage change in concentration of $\mathrm{PM}_{2.5}$ in five Indian megacities. There were few rainfall events recorded during the pre-lockdown period, resulting in a decrease in the average $\mathrm{PM}_{2.5}$ levels compared with the matching BAU period. However, during monsoon, the highest drop can be attributed to both monsoon and low background concentration of $\mathrm{PM}_{2.5}$ in the atmosphere due to lockdown.

\section{Meteorological conditions and $\mathrm{PM}_{2.5}$ levels during the lockdown period}

Meteorological parameters play a significant role in the reduction of fine ambient particles. Figure 4 shows the variations in daily average temperature and relative humidity and rainfall along with $\mathrm{PM}_{2.5}$ concentrations during various phases of the study period in all five megacities. The average temperature ranged from $20.7 \pm 2.3$ to $28.5 \pm 0.6^{\circ} \mathrm{C}$ in all megacities before the lockdown period and increased to $29.0 \pm 3.8$ to $31.7 \pm$ $2.1^{\circ} \mathrm{C}$ during the lockdown period, as shown in Table 4 . During unlocking except for New Delhi, the average temperature decreased in all megacities compared to that during the lockdown period. The relative humidity was lower in the lockdown period in all megacities as it was the season of dry summers in India.

During lockdown except for Mumbai, there were short rain events that were observed in all megacities, which also played a significant role in the reduction of $\mathrm{PM}_{2.5}$ during the lockdown period. Kolkata shows the highest total rainfall of $429.1 \mathrm{~mm}$, followed by New Delhi $(71.4 \mathrm{~mm})$. During the unlocking period, falling in monsoon season, rain (ranging from 603 to $2949 \mathrm{~mm}$ ) played a major role in washout the particulate matter from the atmosphere and hence reduced the $\mathrm{PM}_{2.5}$ concentration. As discussed earlier, only Chennai showed an increase in $\mathrm{PM}_{2.5}$ concentration during the unlocking period compared to the lockdown period. This
Table 2 Percentage change in concentration of $\mathrm{PM}_{2.5}\left(\mu \mathrm{g} \mathrm{m}^{-3}\right)$ in five Indian megacities during different phases of lockdown and unlocking period

\begin{tabular}{|c|c|c|c|c|c|c|c|}
\hline \multirow[t]{3}{*}{ Locations } & \multicolumn{7}{|c|}{ Percentage change in $\mathrm{PM}_{2.5}$ concentration (\%) } \\
\hline & \multicolumn{5}{|c|}{$\begin{array}{l}\text { During the lockdown period compared to before the } \\
\text { lockdown period }\end{array}$} & \multicolumn{2}{|c|}{$\begin{array}{l}\text { During the unlocking period } \\
\text { compared to the lockdown period }\end{array}$} \\
\hline & $\begin{array}{l}\text { Before } \\
\text { lockdown }\end{array}$ & LDN1 & LDN2 & LDN3 & LDN4 & $\begin{array}{l}\text { Overall } \\
\text { lockdown }\end{array}$ & $\begin{array}{l}\text { Overall } \\
\text { unlocking }\end{array}$ \\
\hline Chennai & $21.8 \pm 10.0$ & -11.1 & -60.8 & -60.7 & -4.5 & -34.2 & +22.7 \\
\hline Hyderabad & $34.3 \pm 10.9$ & +2.9 & -19.6 & -22.8 & -3.1 & -9.9 & -60.9 \\
\hline Kolkata & $65.1 \pm 30.1$ & -36.9 & -70.9 & -71.6 & -78.1 & -62.0 & -42.7 \\
\hline Mumbai & $48.6 \pm 20.6$ & -24.4 & -52.0 & -58.9 & -69.8 & -49.3 & -52.9 \\
\hline New Delhi & $60.0 \pm 18.4$ & -37.1 & -32.0 & -15.5 & -13.1 & -26.3 & -30.9 \\
\hline
\end{tabular}


Table 3 Average $\mathrm{PM}_{2.5}$ concentration during different phases of study and its comparison with matching business as usual (BAU) period along with percentage change in concentration of $\mathrm{PM}_{2.5}\left(\mu \mathrm{g} \mathrm{m}^{-3}\right)$ in five Indian megacities

\begin{tabular}{|c|c|c|c|c|c|}
\hline & Chennai & Hyderabad & Kolkata & Mumbai & New Delhi \\
\hline Average $\mathrm{PM}_{2.5}$ concentration $\left(\mu \mathrm{g} \mathrm{m}^{-3}\right)$ in Pre-Lock down (PLDN) & $21.8 \pm 10.0$ & $34.3 \pm 10.9$ & $65.1 \pm 30.1$ & $48.6 \pm 20.6$ & $60.0 \pm 18.4$ \\
\hline Average $\mathrm{PM}_{2.5}$ concentration $\left(\mu \mathrm{g} \mathrm{m}^{-3}\right)$ in BAU-PM (PLDN matching period) & $22.4 \pm 4.5$ & $58.5 \pm 7.6$ & $76.0 \pm 9.4$ & $68.8 \pm 24.4$ & $80.1 \pm 18.2$ \\
\hline Percentage change in PLDN from BAU-PM (\%) & -2.6 & -41.3 & -14.3 & -29.3 & -25.1 \\
\hline Average $\mathrm{PM}_{2.5}$ concentration $\left(\mu \mathrm{g} \mathrm{m}^{-3}\right)$ Lockdown (LDN) & $14.4 \pm 8.7$ & $30.9 \pm 8.1$ & $24.7 \pm 13.7$ & $24.6 \pm 9.7$ & $44.2 \pm 16.3$ \\
\hline Average $\mathrm{PM}_{2.5}$ concentration $\left(\mu \mathrm{g} \mathrm{m}^{-3}\right)$ in BAU-LM (LDN matching period) & $20.3 \pm 4.8$ & $50.9 \pm 7.8$ & $39.7 \pm 7.3$ & $33.0 \pm 13.6$ & $79.4 \pm 21.0$ \\
\hline Percentage change in $L D N$ from $B A U-L M(\%)$ & -29.0 & -39.3 & -37.7 & -25.3 & -44.3 \\
\hline Average $\mathrm{PM}_{2.5}$ concentration $\left(\mu \mathrm{g} \mathrm{m}^{-3}\right)$ in Unlock (ULC) & $17.5 \pm 5.8$ & $11.8 \pm 5.0$ & $13.2 \pm 8.2$ & $12.5 \pm 6.1$ & $31.1 \pm 13.4$ \\
\hline Average $\mathrm{PM}_{2.5}$ concentration $\left(\mu \mathrm{g} \mathrm{m}^{-3}\right)$ in BAU-UM (ULC matching period) & $25.8 \pm 3.7$ & $25.4 \pm 5.9$ & $29.7 \pm 6.4$ & $24.8 \pm 6.8$ & $41.7 \pm 14.0$ \\
\hline Percentage change in ULC from BAU-UM (\%) & -32.1 & -53.5 & -55.7 & -49.8 & -25.3 \\
\hline
\end{tabular}

could be linked to the limited (least) rainfall in this megacity. It can be inferred from the rainfall data that it has a significant impact on $\mathrm{PM}_{2.5}$ levels and its concentration decreased with the increasing amount of rainfall irrespective of anthropogenic air pollution.

\section{Air quality in lockdown and implication for better air quality}

During the lockdown period, this work and other recent studies highlighted the impact of restricted anthropogenic activities on air quality across India and other parts of the world (Sharma et al. 2020; Jain and Sharma 2020; Mahato et al. 2020; Dantas et al. 2020; Chauhan and Singh 2020; Mor et al. 2020). In India, particulate matter $\left(\mathrm{PM}_{2.5}\right.$ and $\left.\mathrm{PM}_{10}\right)$ and $\mathrm{NO}_{2}$ show a significant reduction of up to $40-50 \%$ in the many megacities during the lockdown period as highlighted by Jain and Sharma (2020), Mahato et al. (2020), Singh et al. (2020a), and Biswal et al. (2020). The air quality index (AQI) improved by $15-44 \%$ in India's different parts (Sharma et al. 2020). Generally, air quality in megacities is affected by emission sources, atmospheric reactivity, and meteorology.

In India, significant air pollution reduction during COVID19 lockdown is primarily due to the decrease in major anthropogenic activities such as vehicles, industries, and other fugitive sources such as household cooking, emissions from local industries, food eateries (street food vendors, semi-open cooking in restaurants using tandoors), including other nonexhaust emissions. The meteorology also played an important role in emission reduction during the lockdown as intermittent rain events were also observed during the lockdown in some parts of India. Sharma et al. (2020) also reported that meteorology was favorable during the lockdown; otherwise, the predicted $\mathrm{PM}_{2.5}$ levels could be around 33\% higher than levels reported during the lockdown, respectively.

As discussed above, the source contribution to the total $\mathrm{PM}_{2.5}$ emission load varies from city to city due to their traffic density, industrial activity, and population lifestyle. Local meteorology and local emission sources such as traffic have a substantial role in building $\mathrm{PM}_{2.5}$ concentration at urban sites. Table 5 shows the business as usual source apportionment/ contribution of various sources of $\mathrm{PM}_{2.5}$ in studied megacities. As depicted in Table 5, the $\mathrm{PM}_{2.5}$ from vehicular exhaust and dust emission (non-exhaust emissions, construction) contributes more than $40 \%$ in Delhi, Hyderabad, and Mumbai, whereas, for Kolkata and Chennai, industrial emission has the highest share. During the lockdown, it can be expected that the majority of industrial emissions, exhaust and nonexhaust emissions, all construction and demolition emissions, waste burning emissions were missing. As most industries were closed during the lockdown, the megacities with the highest industrial emissions, i.e., Kolkata, Mumbai, and Chennai, show the highest reduction in lockdown. Also, as the movement was restricted, the exhaust and non-exhaust emissions from vehicle movement also reduced the $\mathrm{PM}_{2.5}$ load in the atmosphere for a megacity like New Delhi.

In agreement with the current study, all the above studies also shed some light on the factors leading to air quality improvement, where air pollution levels remain relatively high and attaining the standard norms is a challenge. In the past, measures like odd-even traffic restrictions and air pollution emergencies were implemented in megacities such as New Delhi. However, this could not make a measurable impact on air pollution levels (Kumar et al. 2017; Sharma et al. 2017). Hence, measures and policies to control air pollution in these megacities cities are needed to be revisited. Furthermore, strategies are required to minimize air pollution in their satellite cities and neighboring regions to have a holistic air pollution control approach.

There is a need to make policies inclined toward disincentivize motorized modes of transport and incentivize the non-motorized mode of transportation. The improvement in air quality during the lockdown also offers that when the AQI category becomes hazardous partial lockdowns could be initiated as a part of the graded 

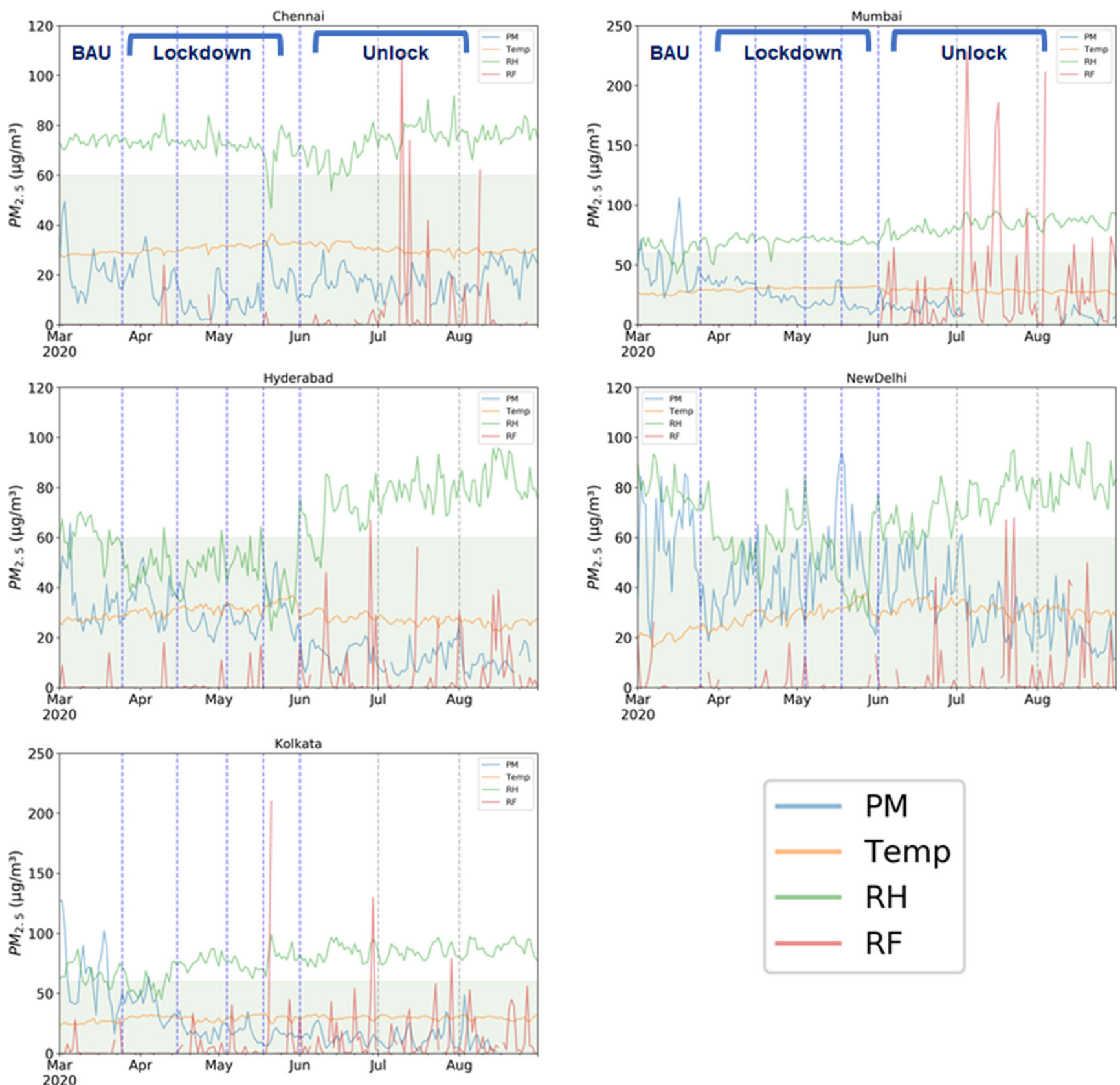

Fig. 4 Variations in daily $\mathrm{PM}_{2.5}$ concentration along with average temperature $\left({ }^{\circ} \mathrm{C}\right)$, relative humidity $(\%)$, and rainfall (mm) during the study period in five Indian megacities

Table 4 Average temperature, average relative humidity, and the total rainfall during different study periods in all megacities

\begin{tabular}{|c|c|c|c|c|c|c|c|c|c|}
\hline \multirow[t]{2}{*}{ Locations } & \multicolumn{3}{|c|}{ Before lockdown } & \multicolumn{3}{|c|}{ During lockdown } & \multicolumn{3}{|c|}{ During unlocking } \\
\hline & $\mathrm{T}\left({ }^{\circ} \mathrm{C}\right)$ & $\mathrm{RH}(\%)$ & Rainfall (mm) & $\mathrm{T}\left({ }^{\circ} \mathrm{C}\right)$ & $\mathrm{RH}(\%)$ & Rainfall (mm) & $\mathrm{T}\left({ }^{\circ} \mathrm{C}\right)$ & $\mathrm{RH}(\%)$ & Rainfall (mm) \\
\hline Chennai & $28.5 \pm 0.6$ & $73.9 \pm 2.0$ & 0 & $31.1 \pm 1.7$ & $72.4 \pm 5.2$ & 41 & $30.3 \pm 1.6$ & $73.8 \pm 6.6$ & 422.0 \\
\hline Hyderabad & $27.5 \pm 1.0$ & $60.8 \pm 6.5$ & 23.5 & $31.7 \pm 2.1$ & $46.1 \pm 8.5$ & 62.8 & $27.0 \pm 1.9$ & $77.3 \pm 9.7$ & 603 \\
\hline Kolkata & $25.6 \pm 1.4$ & $66.5 \pm 8.4$ & 81.4 & $29.5 \pm 2.1$ & $71.2 \pm 12.0$ & 429.1 & $29.7 \pm 1.4$ & $85.4 \pm 6.7$ & 1139.3 \\
\hline Mumbai & $26.1 \pm 1.3$ & $62.1 \pm 8.0$ & 0 & $30.4 \pm 1.1$ & $69.9 \pm 4.7$ & 0 & $28.4 \pm 1.4$ & $83.7 \pm 6.4$ & 2949.0 \\
\hline New Delhi & $20.7 \pm 2.3$ & $79.0 \pm 6.6$ & 97.4 & $29.0 \pm 3.8$ & $55.5 \pm 13.1$ & 71.4 & $31.4 \pm 2.4$ & $75.4 \pm 9.7$ & 552.3 \\
\hline
\end{tabular}




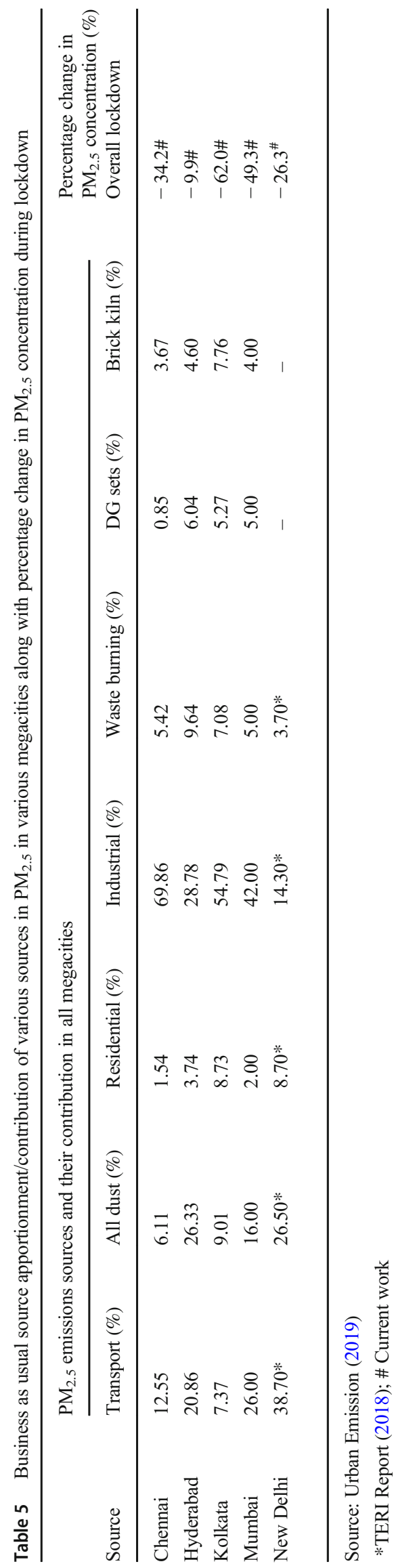

response to improve the poor air quality in megacities like New Delhi. Sharma et al. (2020) reported that the mean excessive risks of PM reduced by $\sim 52 \%$ in India during the lockdown period, although source contribution and chemical toxicity of PM need to investigate during the lockdown and non-lockdown period. This will further answer the query that "does the reduction in air pollution levels also reduces the toxic composition of the PM during the lockdown in the megacities?"

The improvement in air quality during lockdown also urges to understand how the population perceives the air quality. There have been many media reports about the improvement in air quality from several cities, but how it affects the individual behaviors for their contribution to air quality needs to be explored further. Hence, the behavioral aspect of the population during COVID-19 needs to be tapped to engage them toward sustainable practices and transform the momentum to promote air pollution reduction and ensure sustainability.

\section{Conclusion}

The lockdown in India was imposed due to the COVID-19 pandemic. There was an impact of lockdown on daily mean $\mathrm{PM}_{2.5}$ concentrations in five Indian megacities. The $\mathrm{PM}_{2.5}$ concentration reduced significantly in all megacities and met the national standards after the lockdown. The maximum reduction in $\mathrm{PM}_{2.5}$ levels was observed in Kolkata (62\%), followed by Mumbai (49\%), Chennai (34\%), and New Delhi (26\%). Comparatively, Hyderabad exhibited a smaller reduction in $\mathrm{PM}_{2.5}$ concentration, i.e., $10 \%$. However, meteorological parameters such as rainfall and air masses movement also played a significant role in PM reduction. The study reports a new baseline level of $\mathrm{PM}_{2.5}$ for five Indian megacities. This knowledge can be extended to plan future air pollution reduction strategies to minimize the impact of poor air quality on premature mortality and morbidity.

Supplementary Information The online version contains supplementary material available at https://doi.org/10.1007/s11356-020-11808-7.

Acknowledgments The authors would like to thank Health Care Without Harm (HCWH) for supporting the CHAMP Project.

Authors' contributions Ravindra Khaiwal: conceptualization, investigation, visualization, writing original draft, writing, reviewing, and editing; Tanbir Singh: investigation, visualization, formal analysis, writing, reviewing, and editing; Akash Biswal: investigation, visualization, formal analysis, writing, reviewing, and editing; Vikas Singh: investigation, discussion, writing, reviewing, and editing; Suman Mor: conceptualization, investigation, discussion, writing, reviewing, and editing.

Data availability The data is available at the AirNow website (https:// www.airnow.gov/). 


\section{Compliance with ethical standards}

Conflict interests The authors declare that they have no conflict of interest.

Ethical approval Not applicable.

Consent to participate Not applicable.

Consent to publish Not applicable.

\section{References}

Arora S, Bhaukhandi KD, Mishra PK (2020) Coronavirus lockdown helped the environment to bounce back. Science of the Total Environment, p 140573

Bhargava N, Gurjar BR, Mor S, Ravindra K (2018) Assessment of GHG mitigation and CDM technology in urban transport sector of Chandigarh, India. Environ Sci Pollut Res 25(1):363-374

Biswal A, Singh T, Singh V, Ravindra K, Mor S (2020) COVID-19 lockdown and its impact on tropospheric NO2 concentrations over India using satellite-based data. Heliyon:e04764

Chauhan A, Singh RP (2020) Decline in PM2. 5 concentrations over major cities around the world associated with COVID-19. Environmental Research, p 109634

Chen Y, Jin GZ, Kumar N, Shi G (2013) The promise of Beijing: evaluating the impact of the 2008 Olympic Games on air quality. J Environ Econ Manag 66(3):424-443

Chowdhury S, Dey S, Tripathi SN, Beig G, Mishra AK, Sharma S (2017) "Traffic intervention" policy fails to mitigate air pollution in megacity Delhi. Environ Sci Policy 74:8-13

CPCB (Central Pollution Control Board) (2011) Air quality monitoring, emission inventory and source apportionment study for Indian cities: National Summary Report

Dantas G, Siciliano B, França BB, da Silva CM, Arbilla G (2020) The impact of COVID-19 partial lockdown on the air quality of the city of Rio de Janeiro, Brazil. Sci Total Environ 729: 139085

Gargava P, Rajagopalan V (2016) Source apportionment studies in six Indian cities-drawing broad inferences for urban PM 10 reductions. Air Quality, Atmosphere \& Health 9(5):471-481

Gummeneni S, Yusup YB, Chavali M, Samadi SZ (2011) Source apportionment of particulate matter in the ambient air of Hyderabad city, India. Atmos Res 101(3):752-764

Gurjar BR, Ravindra K, Nagpure AS (2016) Air pollution trends over Indian megacities and their local-to-global implications. Atmos Environ 142:475-495

Huang K, Zhang X, Lin Y (2015) The “APEC blue" phenomenon: regional emission control effects observed from space. Atmos Res 164:65-75

Jain S, Sharma T (2020) Social and travel lockdown impact considering coronavirus disease (COVID-19) on air quality in megacities of India: present benefits, future challenges and way forward. Aerosol Air Qual Res 20:1222-1236

Kaur-Sidhu M, Ravindra K, Mor S, John S (2020) Emission factors and global warming potential of various solid biomass fuel-cook stove combinations. Atmospheric Pollution Research 11(2):252-260

Kumar P, Gulia S, Harrison RM, Khare M (2017) The influence of oddeven car trial on fine and coarse particles in Delhi. Environ Pollut 225:20-30
Levy JI, Baxter LK, Clougherty J (2006) The air quality impacts of road closures associated with the 2004 Democratic National Convention in Boston. Environ Health 5(1):16

Li B, Wang F, Yin H, Li X (2019) Mega events and urban air quality improvement: a temporary show? J Clean Prod 217:116-126

Mahato S, Pal S, Ghosh KG (2020) Effect of lockdown amid COVID-19 pandemic on air quality of the megacity Delhi, India. Science of the Total Environment, p 139086

Mardones C, Cornejo N (2020) Ex-post evaluation of environmental decontamination plans on air quality in Chilean cities. J Environ Manag 256:109929

Mor S, Kumar S, Singh T, Dogra S, Pandey V, Ravindra K (2020) Impact of COVID-19 lockdown on air quality in Chandigarh, India: understanding the emission sources during controlled anthropogenic activities. Chemosphere: 127978

Quiros DC, Zhang Q, Choi W, He M, Paulson SE, Winer AM, Wang R, Zhu Y (2013) Air quality impacts of a scheduled 36-h closure of a major highway. Atmos Environ 67:404 414

Ravindra K, Smith KR (2018) Better kitchens and toilets: both needed for better health. Environ Sci Pollut Res 25(13):12299-12302

Ravindra K, Wauters E, Tyagi SK, Mor S, Van Grieken R (2006) Assessment of air quality after the implementation of compressed natural gas $(\mathrm{CNG})$ as fuel in public transport in Delhi, India. Environ Monit Assess 115(1-3):405-417

Ravindra K, Sidhu MK, Mor S, John S, Pyne S (2016) Air pollution in India: bridging the gap between science and policy. Journal of Hazardous, Toxic, and Radioactive Waste 20(4): A4015003

Ravindra K, Kaur-Sidhu M, Mor S, John S (2019a) Trend in household energy consumption pattern in India: a case study on the influence of socio-cultural factors for the choice of clean fuel use. J Clean Prod 213:1024-1034

Ravindra K, Singh T, Mor S, Singh V, Mandal TK, Bhatti MS, Gahlawat SK, Dhankhar R, Mor S, Beig G (2019b) Real-time monitoring of air pollutants in seven cities of North India during crop residue burning and their relationship with meteorology and transboundary movement of air. Sci Total Environ 690:717-729

Ravindra K, Singh T, Pandey V, Mor S (2020) Air pollution trend in Chandigarh city situated in Indo-Gangetic Plains: understanding seasonality and impact of mitigation strategies. Science of The Total Environment: 138717

Sahu SK, Beig G, Parkhi NS (2011) Emissions inventory of anthropogenic PM2. 5 and PM10 in Delhi during Commonwealth Games 2010. Atmos Environ 45(34):6180-6190

Sembhi H, Wooster MJ, Zhang T, Sharma S, Singh N, Agarwal S et al (2020) Post-monsoon air quality degradation across Northern India: assessing the impact of policy-related shifts in timing and amount of crop residue burnt. Environ Res Lett 15. https://doi.org/10.1088/ 1748-9326/aba714/meta

Sharma M, Dikshit O (2016) Comprehensive study on air pollution and greenhouse gases (GHGs) in Delhi. A report submitted to Government of NCT Delhi and DPCC Delhi, pp.1-334

Sharma SK, Agarwal P, Mandal TK, Karapurkar SG, Shenoy DM, Peshin SK, Gupta A, Saxena M, Jain S, Sharma A (2017) Study on ambient air quality of megacity Delhi, India during odd-even strategy. MAPAN 32(2):155-165

Sharma S, Zhang M, Gao J, Zhang H, Kota SH (2020) Effect of restricted emissions during COVID-19 on air quality in India. Sci Total Environ 728:138878

Sidhu MK, Ravindra K, Mor S, John S (2017) Household air pollution from various types of rural kitchens and its exposure assessment. Sci Total Environ 586:419-429

Singh V, Singh S, Biswal A, Kesarkar AP, Mor S, Ravindra K (2020a) Diurnal and temporal changes in air pollution during COVID-19 strict lockdown over different regions of India. Environ Pollut 266(3): 115368 
Singh V, Singh S, Biswal A (2020b) Exceedances and trends of particulate matter (PM2. 5) in five Indian megacities. Science of the Total Environment: 141461

Singh T, Biswal A, Mor S, Ravindra K, Singh V, Mor S (2020c) A highresolution emission inventory of air pollutants from primary crop residue burning over Northern India based on VIIRS thermal anomalies. Environ Pollut 266:115132

Singh T, Ravindra K, Sreekanth V, Gupta P, Sembhi H, Tripathi SN, Mor S (2020d) Climatological trends in satellite-derived aerosol optical depth over North India and its relationship with crop residue burning: rural-urban contrast. Sci Total Environ 748:140963

Singh V, Biswal A, Kesarkar AP, Mor S, Ravindra K (2020e) High resolution vehicular PM10 emissions over megacity Delhi: relative contributions of exhaust and non-exhaust sources. Sci Total Environ 699:134273

Sreekanth V, Mahesh B, Niranjan K (2018) Gradients in PM2. 5 over India: five city study. Urban Climate, 25, pp.99-108., India during odd-even strategy. MAPAN 32(2):155-165
TERI Report (2018) https://www.teriin.org/sites/default/files/2018-08/ Report SA AQM-Delhi-NCR 0.pdf

Urban Emission (2019) https://urbanemissions.info/india-apna/

Vardoulakis S, Kettle R, Cosford P, Lincoln P, Holgate S, Grigg J, Kelly F, Pencheon D (2018) Local action on outdoor air pollution to improve public health. International Journal of Public Health 63(5): $557-565$

Yi D, Sung JH (2018) The local effects of coal-fired power plant shutdown on PM 2.5 concentration: evidence from a policy experiment in Korea. Environmental and Resource Economics Review 27(2): 315-337

Publisher's note Springer Nature remains neutral with regard to jurisdictional claims in published maps and institutional affiliations. 